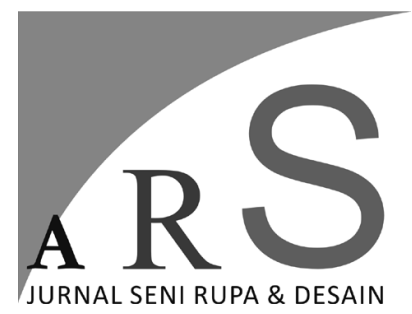

Volume 23 Nomor 3 September - Desember 2020

\title{
IKLAN LAYANAN MASYARAKARAT MENYIKAPI FENOMENA PENGABAIAN PADA ANAK
}

\author{
Fransisca Sherly Taju \\ Program Studi Desain Komunikasi Visual, Jurusan Desain \\ Fakultas Seni Rupa, ISI Yogyakarta \\ Jl. Parangtritis Km.6,5 Sewon bantul Yogyakarta \\ Telepon: 082328311515 \\ E-Mail: Sherly.taju@gmail.com
}

\begin{abstract}
ABSTRAK
Ide penciptaan karya ini berupa perancangan Iklan Layanan Masyarakat (ILM) yang mengungkapkan tentang 'kebiasaan' orangtua yang tak sadar membuat jarak dengan anaknya. Media yang digunakan adalah poster yang disesuaikan dengan target audience, yakni ibu muda yang berada di kota-kota besar/metropolitan, dari kalangan menegah ke atas dan memiliki waktu luang namun kurang peka terhadap anaknya. Dengan menggunakan teknik fotografi 'good eye' yang memiliki kesan realis dan konsep black white agar lebih dapat menonjolkan ajakan bagi ibu untuk tetap sadar akan ikatan emosional langsung dengan anak. Dengan model komunikasi AIDCA: (Attention) (Interest) (Desire) (Conviction (Action) maka perancangan ini diharapkan mampu menyasar audience dengan cara yang tepat. Penggunaan Teori Hegemoni Gramsci diambil guna menyadarkan otoritas orang tua sebagai sarana kultural maupun ideologis dalam berkomunikasi dengan anak, karena munculnya fenomena pengabaian terhadap anak, sehingga aspek komunikasi tidak berfungsi secara maksimal atas perilakunya terhadap anak yang berakibat ikatan emosional dengan anak berkurang. Pada perancangan ini menggunakan perbandingan yang digunakan untuk mengkritik perasaan orangtua, agar nantinya tersadarkan akan peran sesungguhnya yaitu ibu yang paling berhak mendidik anaknya sebagai generasi penerus.
\end{abstract}

Kata kunci: fotografi, good eye, Hegemoni Gramsci.

\begin{abstract}
Public Service Advertisements Responding. The Phenomenon of Neglect in Children. The idea for the creation of this work is in the form of a Public Service Announcement (PSA) design which reveals the "habits" of parents who are not aware of distance from their children. The media used are posters that are tailored to the target audience, namely young mothers who are in big/metropolitan cities, from middle to upper classes and have free time but are less sensitive to their children. By using the "good eye" photography technique which has a realist impression and the concept of black white to further accentuate the invitation for mothers to remain aware of the direct emotional bond with their children. With the AIDCA communication model: (Attention) (Desire) (Conviction (Action), this design is expected to be able to target the audience in the right way. The use of Gramscis Hegemony Theory is taken to make parental authority aware as a cultural and ideological means of communicating with children Due to the emergence of the phenomenon of neglect of children, so that the communication aspect does not function optimally on their behavior towards the child which results in reduced emotional bonding with the child. This design uses a comparison that is used to criticize the feelings of parents, so that later they will be aware of the real role that mothers have the most right to educate their children as the next generation.
\end{abstract}

Keywords : photography, good eye, Hegemoni Gramsci 


\section{Pendahuluan}

Komisi Nasional Perlindungan Anak (Komnas PA) mencatat orang tua telah gagal dalam memberikan perlindungan, pemenuhan dan penghormatan hak anak di Indonesia. Gagal dalam hal ini, yakni orangtua pola asuh/ mendidik anaknya dengan kurang baik sehingga sifat anak tidak dengan mudah diatur, karena orangtua dan anak tidak memiliki ikatan emosional yang terjalin, terbukti dengan kasus anak yang berhadapan dengan hukum di tahun 2019 sebanyak 4.885 kasus. (Dewanto: 2019) Khususnya 896 kasus pelanggaran hak anak dalam keluarga dan pengasuhan. Sedangkan dalam Pasal 45 ayat (1) Undang-Undang Republik Indonesia no 1 tahun 1974 tentang perkawinan, dikatakan bahwa kedua orang tua wajib memelihara dan mendidik anak-anak mereka sebaik-baiknya. Namun, kenyataannya masih banyak anak yang diabaikan. Pengabaian ini mempengaruhi tumbuh kembang, terutama pola hidup dan sifat anak.

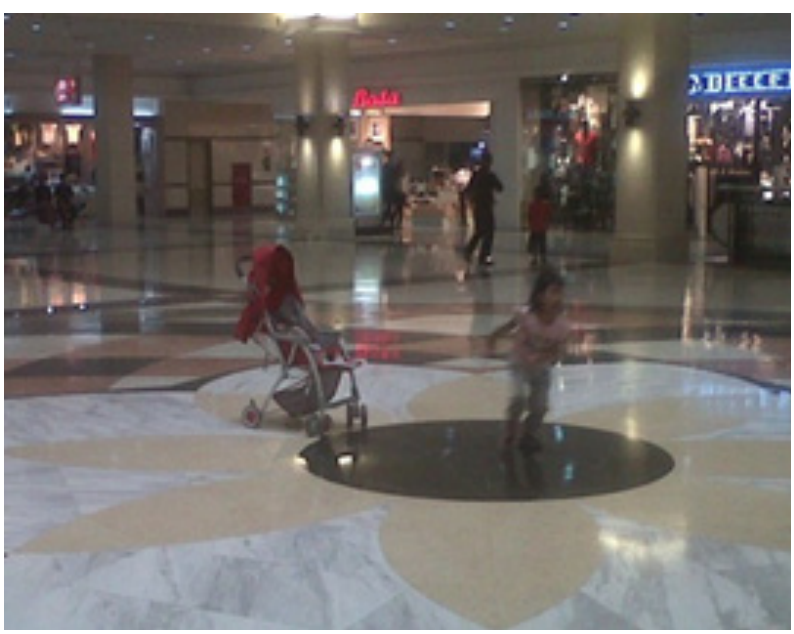

Gambar 1. Anak terlepas dari orang tua

(Sumber: Sherly Taju, 07 Oktober 2014)

Pendidikan dalam keluarga sangat menentukan sikap seseorang, karena orangtua menjadi basis nilai bagi anak. Pola asuh, peran dan tanggung jawab yang dijalankan oleh orang tua dalam menerapkan disiplin pada anak bukan merupakan pekerjaan yang mudah, dimana kadang kala orang tua mengalami hambatan. Hambatan-hambatan tersebut berujung pada perlakuan yang salah kepada anak. Semua tindakan kekerasan kepada anak-anak direkam dalam bawah sadar mereka dan dibawa sampai kepada masa dewasa, dan terus sepanjang hidupnya. Kekerasan yang menimpa anak-anak, baik dari keluarga, sekolah, maupun lingkungan sekitar, terus mengalami peningkatan dari tahun ke tahun. Dimana orangtua seharusnya menjadi seorang yang paling bertanggung jawab atas tumbuh dan berkembangnya anak. (Gumelar: 2013)

Orang tua, khususnya seorang ibu, sejatinya memegang roda dalam keluarga, seperti melahirkan anak, membesarkan serta mengurus rumah tangga. Tidak dapat dipungkiri bahwa ibu saat ini bertolak dari ibu zaman dahulu. Dampak perkembangan zaman juga mempengaruhi peranan seorang ibu, problematika yang sangat terlihat sekarang ini adalah seorang ibu memiliki multiperan yaitu sebagai ibu rumah tangga, sebagai anggota masyarakat, serta sebagai wanita karier. Salah satu akibat dari kemultiperanan ini yakni bergesernya peran mengasuh anak. Peran sebagai pengasuh anak yang menjadi kewajiban seorang ibu dimasa lalu kini berkurang dan digantikan oleh pengasuh anak/babysiter atau melalui jasa penitipan anak.

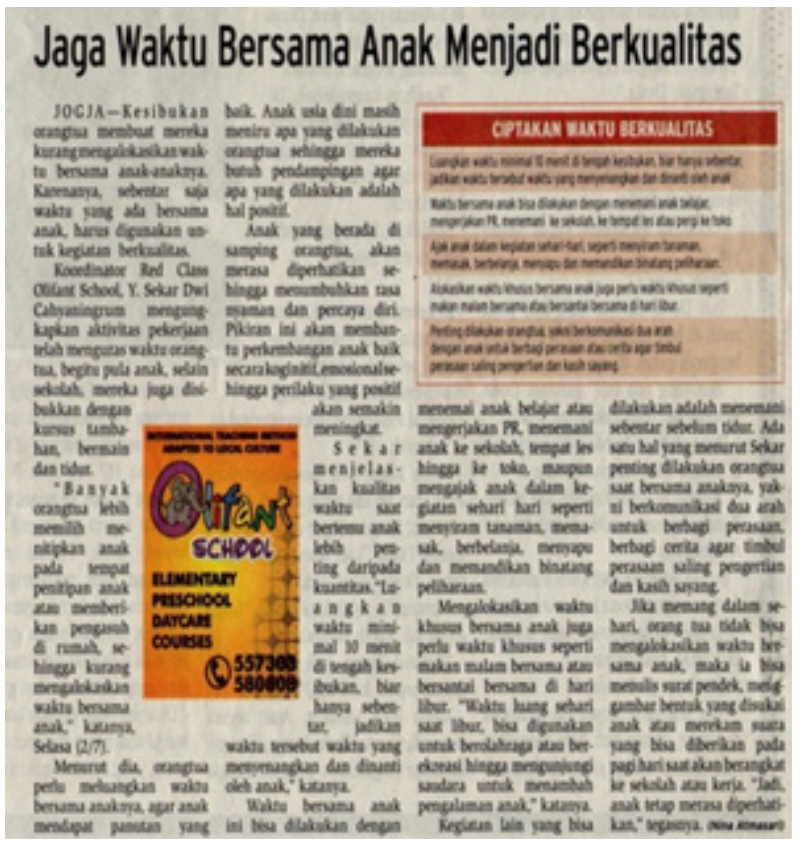

Gambar 2. Artikel Olifant

(Sumber: Koran Harian Jogja 03 Juli 2013)

Sebagai akibat dari bergesernya pola asuh ini, maka keterlibatan dan ikatan emosional antara anak dan sang ibu menjadi berkurang. Sang ibu yang seharusnya menjadi sosok pengasuh yang selain memberikan asuhan tapi juga memberikan 
teladan, pendidikan dan ajaran moral menjadi tergantikan dengan pola asuhan yang bersifat "kerja" dan "akademis". Dimana pengasuh anak/ babysiter hanya mengasuh berdasarkan kontrak kerja serta dibatasi durasi waktu yang terbatas sesuai kesepakatan antara ibu dan si pengasuh. Selain itu pengasuh anak/babysiter terbiasa hanya mengasuh berdasarkan pelajaran atau pendidikan yang diterimanya pada masa pendidikan merawat/ mengasuh anak. Tidak ada ikatan emosional yang terjadi antara anak dan pengasuhnya, jika pun ada tentunya tidak seerat ikatan emosi antara anak dan ibu kandungnya.

Peran seorang ibu sebagai pengasuh dan pembentuk masa depan anak yang tidak bisa digantikan begitu saja dengan peran seorang pengasuh atau tempat penitipan anak. Untuk menumbuhkan kesadaran bagi ibu dibutuhkan sebuah penyadaran betapa pentingnya hubungan anak dan orang tua.

Ide penciptaan karya ini berupa perancangan komunikasi visual yang nantinya berwujud poster dan ambiance media menggunakan teknik fotografi sebagai ajakan bagi ibu untuk tetap sadar akan ikatan emosional langsung dengan anak. Target audience yang dituju adalah ibu muda dari kalangan menegah keatas dan memiliki waktu luang serta kurang peka terhadap anaknya. Penggunaan Teori Hegemoni Gramsci yang menyadarkan pentingnya otoritas orang tua yang kuat, bila diabaikan akan berakibat ikatan emosional dengan anak lambat laun menjadi berkurang. Dengan kampanye ini nantinya orang tua umumnya dan perempuan (para ibu) tersadarkan akan peran sesungguhnya dalam masyarakat yaitu sebagai ibu dari generasi penerus.

\section{Pengabaian Anak}

Dalam buku Understanding The Medical Diagnosis Of Child Maltreatment (Charmaine, 2006) ada lima bentuk pengabaian terhadap anak atau penganiayaan emosional yang dapat dilakukan orangtua atau pengasuh pada anak, yakni sebagai berikut:

1. Rejecting yaitu orangtua menunjukkan perilaku menolak anak, sengaja menceritakan dengan berbagai cara bahwa dirinya tidak diharapkan orangtua bahkan meninggalkan anak, memanggil namanya dengan sebutan tidak berharga, tidak berbicara pada anak, menganggapnya sebagai kambing hitam dan penyebab dari masalah keluarga.

2. Ignoring yaitu orangtua tidak menunjukkan kedekatan dengan anaknya dan tidak menyukai anak-anak. Dapat juga orangtua hanya secara fisik saja bersama-sama anaknya, padahal hati dan pikirannya tidak berada disitu.

3. Terrorizing yaitu orangtua sering mengkritik secara tidak proposional, menghukum, mengolok-olok dan mengharapkan anak memiliki kemampuan sebenarnya.

4. Isolating yaitu orang tua tidak menginginkan anaknya beraktivitas secara proposional bersama rekan-rekan sebayanya.

5. Corrupting yaitu orang tua mengajarkan peraturan yang salah (melanggar norma) pada anaknya.

Sebagian besar pelaku penganiayaan terhadap anak adalah orang yang sangat dipercaya dan berpengaruh terhadap anak. Data menunjukan bahwa $75 \%$ pelaku adalah orangtuanya sendiri, $10 \%$ anggota keluarga lain $2 \%$ orang dekat dengan anak misalnya guru dan pengasuh, dan $13 \%$ orang lain.

Dalam perancangan ini, batasan anak dimaksud terabaikan adalah anak balita yang seharusnya masih sangat dekat dan diperhatikan orangtua, namun dalam kehidupan keseharian, balita tersebut lebih dekat dengan babysitternya dan orangtua hanya sebagai orangtua pajangan, yakni sekedar formalitas, namun ikatan emosional tidak tercipta. Sehingga didikkan babysitterlah yang akan melekat dikarakter anak.

\section{Hegemoni Gramsci}

Hegemoni berasal bahasa Yunani, egemonia yang berarti penguasa atau pemimpin. Pengertian hegemoni adalah bentuk penguasaan terhadapkelompoktertentudengan menggunakan kepemimpinan intelektual dan moral secara konsensus. Artinya, kelompok-kelompok yang terhegemoni menyepakati nilai-nilai ideologis penguasa. Kekuatan hegemoni adalah bagaimana ia menciptakan cara berpikir atau wacana tertentu yang dominan, yang dianggap benar. (Gramsci, 1999) 
Sikap otoriter sering dipertahankan oleh orang tua dengan dalih untuk menanamkan disiplin pada anak. Sebagai akibat dari sikap otoriter ini, anak menunjukkan sikap pasif (hanya menunggu saja), dan menyerahkan segalanya kepada orang tua. Tingkah laku yang tidak dikehendaki pada diri anak dapat merupakan gambaran dari keadaan di dalam keluarga. Hal yang paling penting adalah bahwa kehidupan seorang anak hendaknya tidak diatur oleh kebutuhan orang tua dan menjadikan anak sebagai objek untuk kepentingan orang tua.

Terlihat jelas bahwa orang tua yang memiliki masalah berat dalam hubungannya dengan anak-anak mereka adalah orang-orang yang memiliki konsep-konsep yang sangat kuat dan kaku mengenai apa yang benar dan apa yang salah. Semakin yakin orang tua atas kebenaran nilai-nilai dan keyakinan mereka, semakin cenderung orang tua itu memaksakannya pada anak mereka. Orang tua semacam itu biasanya juga cenderung untuk tidak dapat menerima tingkah laku yang nampaknya menyimpang dari nilai-nilai dan keyakinan mereka.

Ketidakmatangan emosional orang tua mengakibatkan perlakuan-perlakuan orang tua yang kurang terhadap anak-anak, misalnya sangat menguasai anak secara otokratis dan memperlakukan anak dengan keras. Emosi orang tua yang kuat membuat anak takut sehingga mereka menjadi tidak peka terhadap perasaan-perasaannya karena baginya tidak aman mengekspresikan perasaannya itu.

\section{Good Eye}

Berkarya tak lepas dari hal komposisi, berdasarkan 'Good Eye', komposisi dapat dibagi menjadi tiga hal: pertama, konten (hal utama, karena ketika seseorang melihat karya, pertama yang ditanyakan adalah kontennya), kedua, warna (salah satu komposisional gambar yang krusial dan dapat digunakan untuk 'penekanan' pada elemen gambar; hue, saturation, value), dan ketiga, organisasi spasial (melibatkan 'pandangan geometris' dalam hal penempatan volume, garis, dan sebagainya pada suatu ruang; focalizer gambar: memfokuskan pandangan pada gagasan tertentu dari suatu gambar. (Gillian: 2001)

Dalam karya Iklan layanan Masyarakat (ILM) ini, menggunakan teknik fotografi yang berkonsep pada 'good eye' terutama dalam konten, yaitu pesan yang akan disampaikan tentang kesadaran untuk mengurangi pengabaian anak oleh orangtuanya. Warna yang digunakan black and white namun disini mencerminkan value yang kuat, untuk menekankan konten yang ingin dicapai.

\section{Target Audience}

Jenis kelamin : Perempuan

Usia : 20 - 30 tahun

Status sosial : Menengah keatas

Pekerjaan : Ibu rumah tangga

Domisili : Jakarta

Psikografis: Gaya hidup konsumtif prestis

Behaviour: Ibu muda yang masih menikmati masa muda

\section{Strategi Komunikasi}

Rumusan yang digunakan dalam ILM ini adalah AIDCA, yang terurai sebagai berikut:

Attention (perhatian)

Sebuah iklan atau pesan yang disampaikan harus dapat menarik perhatian audience, untuk itu iklan harus memperhatikan ukuran, penggunaan warna, layout, tipografi, serta lokasi media.

Interest (minat)

Agar audience lebih tertarik dengan pesan yang disampaikan, informasi harus berisi ketertarikan dan menumbuhkan pemahaman yang cukup jelas.

\section{Desire (kebutuhan)}

Pesan disampaikan untuk menggugah kesadaran ibu agar mau lebih peduli pada buah hatinya, agar karakter buah hati akan terbentuk dengan yang diinginkan orangtua.

\section{Conviction (rasa percaya)}

Setelah audience tergugah, tahap berikutnya adalah meyakinkan bahwa masalah pengabaian 
anak yang tidak tersadarkan merupakan masalah yang penting untuk mendapatkan perhatian dan tindakan positif dari orangtua.

Action (tindakan)

Terakhir diharapkan orangtua dapat membentuk sikap yang tanggap dan responsive terhadap masalah pengabaian anak.

\section{Strategi Kreatif}

Dalam kehidupan keseharian, orang tua akan sangat sibuk. Sesuai kodratnya, seorang ayah akan mencari nafkah untuk memenuhi kebutuhan kelurga, sedangkan seorang ibu akan mengurus rumah tangga dan keluarga. Dari bangun tidur hingga tidur lagi, kesibukan keseharian akan berjalan begitu saja. Namun ketika kebisaan itu malah akan membuat jarak yang jauh dengan buah hatinya. Waktu yang banyak seharusnya dihabiskan seorang ibu ketika bersama anakanya, namun sekarang ini dengan adanya jasa babysitter yang mengambil ahli tanggung jawab sang ibu, sehingga ikatan emosional ibu dan anak menjadi semakin jauh. ILM ini akan mengkritik kebiasaan-kebiasaan yang seharusnya digunakan bersama sang buah hati, namun dalam kenyataannya malah menimbulkan jarak.

ILM Mengurangi Pengabaian Anak ini dikonsepkan untuk menunjukan bahwa walaupun orangtua bebas untuk membentuk karakter anaknya, tetap harus cerdas dalam menggunakan waktu bersama buah hati. Pemilihan kata cerdas disini adalah sebutan untuk orang yang tidak terlalu teratur dan disiplin, tetapi selalu mampu mengerjakan apa yang benar. Diharapkan untuk kesadaran orangtua lebih peduli pada buah hati agar terbentuk karakter yang baik pada buah hati.

Tagline dalam ILM Mengurangi Pengabaian Anak yang akan digunakan dalam desain karya, yakni: 'Seberapa Dekat Anda Dan Si Buah Hati'. Tagline ini berkisar tentang kritikan untuk orangtua Di Jakarta. Disesuaikan dengan karakter orang Jakarta yang to the point, sehingga menggunakan bahasa yang sesuai, yakni jelas dan 'berbunyi'.

\section{Karya Desain}

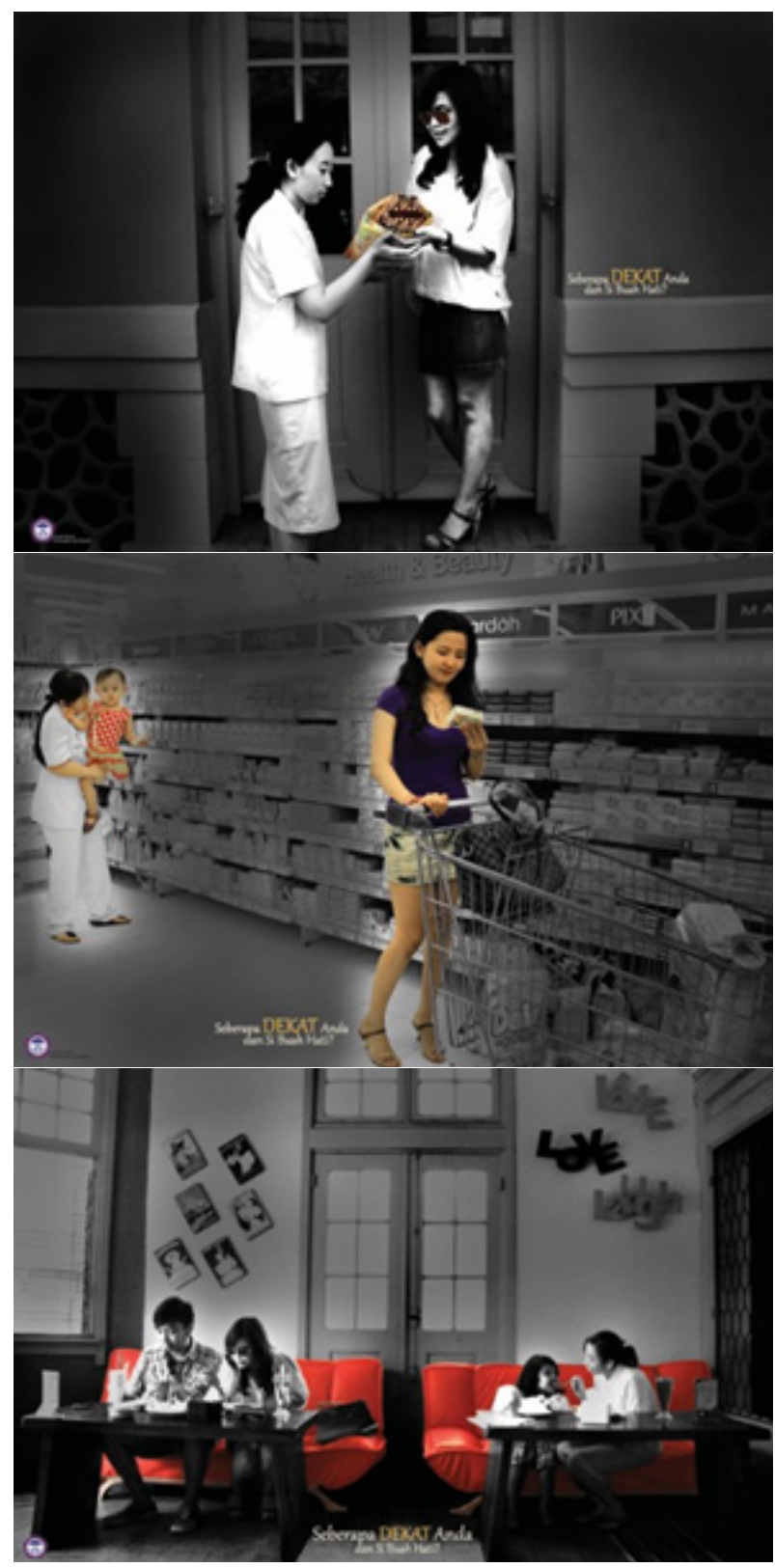

Gambar 3. Poster ILM Mengurangi Pengabaian Anak (Sumber: Sherly Taju)

Warna

Secara visual, warna yang dipilih warna yang berkesan gelap, hal ini mendukung suasana dramatis serta langsung memberikan respon psikologis karena mampu mempengaruhi citra orang yang melihatnya.

\section{Copywriting}

Gaya bahasa yang dipilih merupakan gaya sindiran dengan pendekatan emosional, hal ini dipilih agar dapat menyentuh hati dan kesadaran orangtua. 


\section{Tipografi}

Font yang digunakan memberikan kesan tegas namun lembut, karena disesuaikan dengan ubu-ibu muda. Pemilihan font Geometr 212 ini mengesankan ketegasan, kepoloasan dan sederhana. Namun dari itu semua adanya garis tegas sehingga memberi kemudahan untuk terbaca.

\section{Ilustrasi Visual}

Ilustrasi visual didasari dari beberapa pertimbangan mengenai unsur keseluruhan dari data yang diperoleh mengenai perancangan ILM. Pemilihan ilustrasi menggunakan fotografi dan teknik 'good eye' yang didasari oleh beberapa pertimbangan, yakni untuk lebih mudah dimengerti dengan bentuk realis karena dapat menciptakan efek dramatis sehingga menumbuhkan kejadian yang terlihat nyata. Hal tersebut didukung dengan penambahan kreatif grafis yang diwujudkan melalui teknik komputer grafis lebih memungkinkan terciptanya sebuah visualisasi yang kuat dan dramatis.

\section{Kesimpulan}

Fenomena pengabaian anak, terutama di kota metropolitan semakin terlihat jelas dan terang-terangan. Pentingnya mengangkat tema ini karena anak merupakan penerus bangsa yang harus diperjuangkan. Namun banyak anak yang sedari kecil sudah masuk tahanan, karena melakukan kejahatan. Hal ini dikarenakan perhatian orangtua yang tidak didapat, sehingga didikan yang baikpun tidak diberikan oleh orangtua. Ditujukan untuk orangtua dari kalangan atas, terutama ibu muda yang lebih memilih bersenang-senang dan meninggalkan anak diasuh oleh babysitter.

Strategi kreatif untuk memberi kesadaran kepada orangtua melalui iklan layanan masyarakat dengan media poster. Menggunakan pendekatan hegemoni Gramsci yang menjelaskan tentang kekuasaan orangtua dan teknik 'good eye' pada karya, yakni berilustrasikan fotografi sehingga dapat menggambarkan realita yang ada.

\section{Daftar Pustaka}

Antonio, Gramsci. (1999). Selections From The Prison Notebooks. London : The Electric Book Company

Brittain, Charmaine R. (2006). Understanding The Medical Diagnosis OfChild Maltreatment: A Guide For Non Medical Professionals. New York : Oxford University Press

Rose, Gillian. (2001). Visual Methodologies: An Introduction to the Interpretation of Visual Materialas. London : Sage Publications

Linda Amalia Sari Gumelar, Menteri Negara Pemberdayaan Perempuan dan Perlindungan Anak Republik Indonesia 2014, tanggal 2 juli 2013

Internet

Samodro, Dewanto. 2019. KPAI catat 4.369 kasus pelanggaran hak anak sepanjang 2019 https://www.antaranews.com/berita/1303854/ kpai-catat-4369-kasus-pelanggaran-hakanak-sepanjang-2019. Diakses pada 20 Maret 2020 